\title{
The Blang ethnic group's traditional culture characteristics and its change tendency from the perspective of acculturation
}

\author{
Chun-Ai XI, Guo-Qing YIN \\ Yunnan University of Finance and Economics, Yunnan, China. \\ E-mail: xixi1972@126.com459046811@qq.com
}

\begin{abstract}
Amid the trend of globalization, the traditional culture of ethnic groups with small populations face impact. Through analysis of the dispersed communities of the Blang ethnic groups in Shuang Jiang and Shi Dian, the traditional culture of basic necessities of the Blang ethnic groups are gradually lost their original characteristic and are assimilated to the mainstream culture. That is essentially regarded as a process of cultural assimilation, which means the loss of traditional culture depends on our corresponding strategies.
\end{abstract}

Keywords: cultural change, acculturation, the Blang ethnic group

\section{Introduction}

Along with the globalization's deepening, the ethnic minorities in backward regions speed up the pace of pursuing the modernization. At the same time, their traditional culture increasingly disappears in the process of the social culture changes, and it shows an increasingly accelerating trend. Especially because of the small ethnic groups have small population and cultural core, their cultural self-preservation is weak, and then, the loss of traditional culture is more prominent. In the contemporary era, it is particularly important to analyze the tendency of the traditional culture changes and carry on a deep thinking to this.

\section{Characteristics of traditional Blang ethnic group's basic living customs}

\subsection{Characteristics of traditional Blang ethnic group's costume}

Costume is the most prominent cultural symbol of a nation, the Blang ethnic group costume is not only a significant part of Blang people's culture, but also a representation that makes Blang ethnic group different from other nations.The Shuangjiang Blang people costume shares some characteristics of a Dai costume, with men' costumes mainly black: black shirt with round collar and long sleeves, pant with loose crotch and leg openings, and long headband, besides, a few people wear earrings. Women' costumes are colorful while social rules are distinguished by different colors: middle and old aged women wear black or dark blue blouse with round collar and narrow sleeves, while young ladies are fond of blue or white underside with colorful prints interspersing on the collars and cuffs. Unmarried girls are brightly dressed in tight skirt and blouse with curve bottom. They wear silver bracelets and earings, headscarf and apron, with legs wrapped by cloth for protection. Both men and women are used to be barefooted. Their costumes are all homespun. Comparatively, costumes of Shidian Blang ethnic group are more colorful, women' costumes here are known as "Huapuman" for bright color contrast and complicate decoration. An ordinary women' costume consists of headscarf, coat, blouse, apron and pant. This makes it easy to tell one's identity from the costume: Unmarried girls wrap their braids around headscarf, with silver bubbles,colored thread and colorful chains, while married women keep their braids on top and head wrapped by black cloth with no decoration. The apron of unmarried girls is decorated with lace around while that of married women inside. The aged women will not wear flowers but show more interest in necklace, bracelets and earrings, their costumes are mainly in dark color. On their collars, there are 12 silver bubbles(representing 12 months), on the sleeves, there are 24 buttons(representing 24 solar terms). On each side of the collars, there is a silver chain for hanging sewing box, which makes it possible for women to do needle work whenever they want. And here is the men' costume: white shirt with black coat on top of it, black headband decorated with red tassel on the end, loose pant and straw sandals. ${ }^{[1]}$

\subsection{Characteristics of traditional Blang ethnic group's} food

"Food is everything", the environment where the Blang people lives in decides the characteristics of their food: ingredients obtained naturally, tasting mainly hot and sour, and cold and pickled principally. The food tastes fresh and the original flavor is greatly remained. No matter for Shuangjiang or Shidian Blang ethnic group, wild plants and insects all counts a great deal in their traditional food ingredients, which presents us the way they live naturally and obtain local ingredients. However, the flavor and cooking methods reflect their regional features and preserve the nutrition of food well.

\subsection{The characteristics of traditional dwellings of the Blang ethnic group}

Dwellings is the wisdom and crystal of ethnic culture, it has accumulated the historical rudiment of development 
and shift of ethnic culture."chicken coop" is the most characteristic of dwellings of Shuangjiang Blang ethnic group, this kind of dwelling is an oval thatched cottage with floor type, it is named by its outline for is exactly like the "coop" which used for cover the chicken in the rural area. The construction is very simple, building materials including wood, bamboo and thatch, the architecture art is also very random, mainly use the way of bale, bind and bundle. It often use the cedrela and teak as its pillar, set up three girders, the wood rafter is about 5 meters, the effluent is quite steep, the height of center pillar is more than 3 meters, the roof is made from thatch. The below part of roof often use the board or soil matrix as its wall.The door is made from bamboo chip, there is an oven to boil pigwash once you enter the door, step further, and you will see the main room, the center of house will set a fireplace. The bed is lay against the wall or just make the bed at the floor. There are some stools near the fireplace, where often receive guests and dining.The other side of main room have warehouse and side house to store sundries and grains, down stair of warehouse is used for close cattle ${ }^{[2]}$. Build the "chicken coop" is very easy, almost all adult males of Blang ethnic group can build it before 1970s. Because of it is the dwelling of whole family, the whole family members' fortune and misfortune are dominated by it, so building a house is a significant thing and derived miscellaneous taboos and a series of sacrificial ceremonies which is more important and complicated than building house itself. There are many attentions and taboos should be concerned, like when to draw materials, how to make sacrifice before draw materials, how to choose the materials, when to build the house, the requirements of set up center pillar and so on. After the house has constructed, the traditional ceremony of'enter new house" should be hold, until then the whole process of build house has accomplished successfully. This makes the "chicken coop" with deep cultural connotation, although it seems a simple dwelling symbol, it also reflected the intense cultural features of Blang ethnic.Shidian Blang people lived in a traditional construction, which is called"one step floor" (a step floor), this kind of stilt house is build on the mountain foot with timberwork. People were lived in the upstairs, one room for store grains which is charged by housekeeper or unmarried daughter, one room for setting fireplace which is charged by the head of family, the fireplace keep flame burning all the year around, the cattle were kept in the downstairs. There are also a series of complicated process and taboos in building the "one step floor". Pick the foundation, select material, choose an auspicious day, set up house, enter new house and so on, each procedure have corresponding custom and some ceremony. It reflected the status of "house" in the eyes of Blang ethnic group which serve as the whole family's dwelling, it also contain boundless hope and dignified connotation of the whole family.

\subsection{Traditional transportation ways of Blang ethnic group}

The Blang ethic group is lived in the mountainous area, before the found of $\mathrm{PRC}$, the mainly transportation vehicle is cattle and horse, people often travel on foot. So the transportation is always the bottleneck to contact with outside.

\section{The tendency of the Blang's basic necessities changes.}

Plekhanov once said, “ a nation's arts are determined by its psychological, the psychological is caused by its situation, and in the end its situation is restrained by its productivity conditions and the relations of production."[3] Basic necessities are material culture phenomenon, their generation and variation are always adapted to the development of the social economy. Along with the development of the times, it has a clear or an implicit change in the Blang ethnic group's basic necessities.

\subsection{Costumes is simplified by removing complications, ethnic characteristics are disappearing, growing convergence in the mainstream}

costumes is the most explicit and most active factor in the national culture, significantly change in national culture also tend to change from changing costume culture.Traditional costume plays an important role in Blang's history, although it can be find a little bit from the old, but it is nearly impossible to find young people dressed in clothes with national features, almost all of them dressed in jacket or suit, for teenagers, more of them choose to wear T-shirts and jeans. When asking the reason of choosing modern clothes instead of traditional costumes (they still dress traditional costumes in festivals), the answers from the majority says: "it may cause inconvenience when dressing up." "Traditional costumes looks so rube" "Clothing these traditional costumes takes time, and it is convenience when dressing Han clothing".

\subsection{Diet structure changed, cooking method becoming diversified and subsidiary food dependence of market has increased.}

With the development of society, huge changes have taken placed in Blang's diet structure, as rice production increased and easier to trade food, it is hard to see Blang people take grain crops (usually corn) as staples, which they used to. Rice became staples all the year round. As ecological environment has changed and the implementation of the relevant national protection policy at same time, prey dish can hardly be placed on the dining table, all kinds of wild vegetables and wild ingredients was replaced by cultivated vegetables as well; With the development of external exchange, Blang's ordinary family tend to change their cooking method from cold curing to multiple cooking ways, such as frying, steam, braising and so on. With the development of market trading, subsidiary food are diversified, not only do they able to local foods, but also vegetables and foods 
out of season from other places, which indicates that subsidiary food dependence of market has increased.

\section{3 "one step floor" and "chicken coop" are becoming the witness of history .}

"one step floor" from Shidian and "chicken coop" from Shuangjiang are both distinctive Blang style house, which accommodate the special geographical environment Blang people live in. Since 1980s, with improvement of economic conditions and traffic situations, almost all the Blang traditional house were taken placed by modern structure house, which is formed in civil structure, masionry structure even reinforced concrete structure. Obvious changes have also taken place in inner furnishing, electric appliance, modern calendar and star posters increasingly occupy inner space of house, Blang people tend to spend their spare time in living room filled with modern media, while Huotang (a kind of Chinese fireplace, usually placed in the middle of the room) is losing its' place in people's minds, which stand for sacred and solemn meaning.

\subsection{With the popularity of modern means of transport, traditional transport way is replaced by modern wheel.}

On account of Blang people living in mountainous area, external traffic mostly rely on animals and manpower, in recent years, with the development of economic and strongly support from country, Traffic in Blang region has improved year after year. Roads inside village are covered by cement while roads outside village covered by stones. It is not rare to find people owning modern transportation equipment like motorcycle and tractor. Take Bangxie as example, there are 5 motorcycles in their village in 2005 , increased to 40 motorcycles in 2006 , then rapidly increased to more than 100, every family own at least one motorcycle in nowadays. Motorcycle becomes the basic transportation to Blang people. Some families also bought farm vehicles and wheeled tractor, the range of activity of Blang people has been greatly extended, external exchange is reinforced as well.

\section{Conclusion: Thinking about changes taken place in Blang people basic necessities of life.}

Origin of all the cultures are determined by certain productive force and productive relations, rely on certain habitat, once this habitat start to change, the culture derive from it will change inevitably. Thus, social culture changes is a kind of normal social phenomenon. There are five of motivation theory about cultural change by Sze-ma Yunjie, biological determinism, geographical determinism, psychological determinism, cultural transmission determinism and industrial development determinism $^{[4]}$. There are scholars believe that culture changes can be divided into two categories: endogenous changes and exogenous changes, thus changes caused by internal development factors like invention and discovery or changes caused by external development or communication $^{[5]}$. Clyde.M $\cdot$ Woods believes that "changes generally caused by sociocultural environment and natural environment changes...... sociocultural environment refers to human, culture and society while natural environment refers to ecological environment with a certain character, including natural and artificial." ${ }^{\text {[6] }}$ In the process of modernization, huge changes have taken place in traditional Blang's means of livelihood and basic necessities of life, they are undergoing changes from economic life, social life and religious belief. Influenced by modernization, Blang people, which is in rural society, accept modernization in their own ways, as a matter of fact, this is a process of acculturation of culture. During this process, Blang's traditional culture is continual exposed to the modern culture, which keep independence previously, when the exposure growing to some extent that enough to cause group acculturation in certain culture, Blang's culture, which is in attached position, started to change. As a result, we can see that Blang's traditional culture is increasingly acculturated by modernization. This acculturation started from individuals, then comes to the group acculturation, the result of acculturation "may obtain long-term stability of the adjustment; perhaps a certain race will suffering from extinction; perhaps it will be assimilate; perhaps it will merged into other cultures as a subculture." For Blang people in Shidian and Bangxie, this change may not means total loss of their culture and inner content, but we must realize soberly that Blang's traditional house, costumes and other traditional things is fading away from people's memory, a lot of intangible cultural heritage like oral composition and textile technology are at the brink of disappearance as the old folk artisans pass away, it is an urgent and important task to us, a task we can not avoid: how to take effective measures to reinforce the protection and inheritance of Blang's traditional culture ?

\section{Acknowledgment}

The research for this article was sponsored by the Project ( No. YB2014063) by the Philosophy of the Social Science of Yunnan and by Talent-Introducing Project of Yunnan University of Finance and Economics ( No. YC2013D20).

\section{References}

[1] Origins of data: Shidian county " the survey of national and folk traditional culture" (internal), April 30,2005 .

[2] Editorial committee: the ethnographic of Shuangjiang county. Kunming: Yunnan Nationalities Publishing House, 1995.147

[ 3 ] Wang Ningsheng, the survey of the cultural anthropology [M].(the additional article ). Beijing, Cultural Relics Press, 2004.134.

[ 4 ] Sze-ma Yunjie, Cultural sociology [M], Jinan: Shandong People Press, 1986.403 414.

[5] Zheng Xiaoyun, Cultural identity and cultural change[M], Beijing: China Social Sciences Press, 1992.201. 